avançados no maxilar em relação à mandíbula a partir dos 9 anos de idade $(p<0,05)$. Não houve diferenças significativas entre rapazes e raparigas $(p>0,05)$ ou entre os lados direito e esquerdo ( $p>0,05)$. A presença de criptas foi observada entre os 7,3 e os 13,9 anos no maxilar e entre 6,7 e os 13,3 anos na mandíbula. A idade cronológica apresentou forte correlação com o desenvolvimento do terceiro molar (rapazes, maxilar $r$ $=0,775$, mandíbula $r=0,788$; raparigas, maxilar $r=0,749$, mandíbula $r=0,781)$. Conclusões: Na população portuguesa, a presença da cripta do terceiro molar é visível a partir dos 7 anos, tanto na mandíbula como no maxilar. A agenesia do terceiro molar pode ser confirmada se a cripta não estiver presente após os 14 anos de idade. A idade cronológica está fortemente correlacionada com o estadio de desenvolvimento do terceiro molar.

http://doi.org/10.24873/j.rpemd.2022.01.953

\section{\#097 Perceção da assimetria facial em crianças com mordida cruzada posterior unilateral}

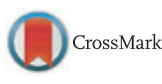

Matilde Cruz Ferreira, Joana Godinho*, Luis Jardim

Universidade de Lisboa Faculdade de Medicina Dentária

Objetivos: Avaliar a perceção da assimetria facial em crianças com mordida cruzada unilateral posterior e determinar se o lado da perceção da assimetria se correlaciona com o lado da má oclusão. Materiais e métodos: A perceção da assimetria facial de 60 crianças entre os 7 e os 10 anos de idade, 30 com mordida cruzada unilateral posterior e 30 sem mordida cruzada (grupo de controlo), foi avaliada por oito especialistas em Ortodontia, a partir de fotografias frontais em repouso, por meio de uma Escala Visual Analógica. As fotografias da face em repouso foram usadas para compor uma apresentação de diapositivos PowerPoint ${ }^{\circledR}$, de modo a quantificar a assimetria usando a Escala Visual Analógica, quando presente, e o lado da assimetria. Para comparar as médias da perceção de assimetria facial entre os grupos de estudo e de controlo, foram realizados t-testes. A direção da perceção da assimetria facial foi comparada através de uma análise de variância, com três grupos: mordida cruzada unilateral esquerda, direita e ausência de mordida cruzada. A concordância entre o lado da assimetria facial percebida e o lado da mordida cruzada foi avaliada pelo teste do Qui-quadrado. O nível de significância estatística foi fixado em $5 \%$. Resultados: A perceção da quantidade de assimetria facial avaliada pela Escala Visual Analógica, foi significativamente maior em crianças com mordida cruzada posterior (média de 14,2 pontos) em comparação com um grupo sem mordida cruzada (média de 7,4 pontos). A concordância entre o lado percecionado como assimétrico e o lado da mordida cruzada foi maior para o lado direito (92.9\%) em relação ao lado esquerdo (43,8\%). A análise de variância, demonstrou diferenças significativas na perceção do lado da assimetria entre os grupos de mordida cruzada posterior direita e mordida cruzada posterior esquerda ( $p<0,001)$, e entre os grupos de mordida cruzada posterior direita e controlo $(\mathrm{p}=$ $0,001)$. Houve uma associação significativa entre o lado percecionado da assimetria facial e o lado da mordida cruzada $(\mathrm{p}=$ 0,001). Conclusões: A perceção da assimetria facial foi mais evidente em crianças com mordida cruzada posterior unilateral, em comparação com crianças sem mordida cruzada. Houve uma associação significativa entre o lado percecionado da assimetria facial e o lado da mordida cruzada. A concordância entre o lado percecionado como assimétrico e o lado da mordida cruzada foi significativa, tendo sido maior para o lado direito em relação ao esquerdo.

http://doi.org/10.24873/j.rpemd.2022.01.954

\section{\#098 Conhecimentos dos professores das escolas de Viseu relativamente à saúde oral infantil CrossMark}

Ana Teresa Albuquerque*, Andreia Figueiredo, Mariana Seabra Universidade Católica Portuguesa

Objetivos: As doenças orais, tão frequentes nas crianças em idade escolar, são na sua maioria suscetíveis de prevenção. Uma vez que as crianças passam grande parte do seu tempo nas escolas, este é o local ideal para o desenvolvimento e implementação de programas educativo-preventivos. Os professores, pela sua relação de proximidade com os alunos, assumem um papel essencial na promoção e educação para a saúde oral, podendo contribuir para a adoção de comportamentos saudáveis que se perpetuarão para o resto da vida. No entanto, para que se tornem agentes promotores de saúde eficazes, é necessário que possuam conhecimentos na área. O objetivo deste estudo foi, por isso, caracterizar os conhecimentos dos docentes no âmbito da saúde oral. Materiais e métodos: Estudo descritivo, observacional, transversal realizado com 475 docentes dos Agrupamentos de Escolas e Colégios privados de Viseu. Os dados foram recolhidos através de um questionário online que permitiu caracterizar os conhecimentos relativamente à saúde oral. Resultados: A amostra revela que apenas $6,7 \%$ dos professores realizou formação em saúde oral. 89,7\% reconhece ser importante estar envolvido na saúde oral das crianças. Os educadores de infância e professores do $1 .^{\circ}$ ciclo são os mais vigilantes em relação à higiene oral dos seus alunos, revelando maior conhecimento na área $(\mathrm{p}<0.001)$. 75,9\% dos professores não inclui a higiene oral na rotina diária escolar apresentando a falta de condições e de recursos humanos como principais motivos. Os docentes que lecionam em escolas em meio rural têm maior perceção conhecimento e melhores práticas relativamente à higiene oral $(\mathrm{p}<0.05)$. Os professores que mostram maior consciencialização relativamente ao número de escovagens de dentes diária e à importância da higienização antes de deitar são os que possuem formação em higiene oral $(p<0.05)$. A maioria dos docentes não possui conhecimento relativamente à quantidade adequada de flúor, idade com que se deve começar a utilizar o fio dentário, momento adequado para a primeira visita ao médico dentista e frequência de consultas. Conclusões: Existe um défice de conhecimentos por parte dos professores relativamente à saúde oral das crianças. Para que exerçam adequadamente o seu papel como agentes promotores de saúde oral, é crucial aumentar a sua literacia na área, através da realização de ações de formação contínua.

http://doi.org/10.24873/j.rpemd.2022.01.955 